\title{
Design de interiores como estratégia de promoção de inovação de startups
}

Interior design as a strategy to promote startup innovation

LINHARES, Talissa Bedran

Universidade Federal de Minas Gerais - UFMG I talissabl@hotmail.com

BARBOSA, Paula Glória

Instituto Federal de Educação, Ciência e Tecnologia de Minas Gerais (IFMG) paulaglbarbosa@gmail.com

TAKAMATSU, Renata Turola

Universidade Federal de Minas Gerais - UFMG I rettakamatsu@gmail.com

\begin{abstract}
Resumo
O presente trabalho tem como objetivo analisar o potencial da atuação do designer de interiores no âmbito empresarial, especialmente na identificação de estratégias que estimulem a inovação e valorizem a identidade corporativa, especificamente em startups. Para tal, buscouse compreender as características e filosofias desse tipo de empresa, por fim, exemplificou-se a aplicação de um projeto de design de interiores em uma delas, abrangendo questões como sua filosofia, ambiente de trabalho e suas limitações estruturais.
\end{abstract}

Palavras Chave: Inovação. Startup. Design de interiores. Produtividade no ambiente de trabalho.

\section{Abstract}

The present paper aims to analyze the potential of the interior designer's practice in the business field, especially in identifying strategies that promote innovation and enrich the corporate identity, specifically in startup companies. To do so, we sought to understand the features and philosophies of this type of business and, finally, apply an Interior Design's project in one of these companies, considering questions such as their philosophy, work environment, and structural limitations.

Keywords: Innovation. Startup. Interior design. Productivity in the workplace. 


\section{INTRODUC̣ÃO}

As startups são um novo conceito de empresas que vêm ganhando destaque progressivamente. No Brasil ainda não são amplamente conhecidas, e muitas pessoas reagem com preconceito ao serem apresentadas a esse tipo de empresa. A filosofia de trabalho de uma startup, se não compreendida a fundo, pode gerar dúvidas, inicialmente. É difícil associar responsabilidade e comprometimento a uma empresa na qual as pessoas trabalham de bermuda e jogam videogame em pleno expediente.

Diversos fatores devem ser levados em consideração ao definir-se uma startup e sua filosofia de trabalho é um dos aspectos subjetivos imprescindíveis para a compreensão desse termo. Startups são empresas que oferecem um produto ou serviço em um meio incerto, sem precedentes, ou seja, um mercado que lida com inovação (RIES, 2011).

É importante que a palavra inovação seja bem definida para que seja compreendida corretamente. Ries (2011) constata que há diversas formas de inovação em se tratando de startups. A disponibilização de um produto ou serviço em um novo local ou para um novo público, ou o reposicionamento de uma tecnologia conhecida para um novo uso, por exemplo, são formas de inovar, além da inovação por meio de descobertas científicas.

Para Lastres (1999), existem dois tipos de inovação: a inovação radical e a inovação incremental. A inovação radical é a introdução ou desenvolvimento de um novo produto, forma de organização da produção ou processo completamente novo. Esse tipo de inovação pode romper com o padrão tecnológico previamente existente, gerando novos setores, mercados e indústrias. Já a inovação incremental é referente a qualquer tipo de melhoria em um produto, organização da produção ou processo, sem alterações na estrutura industrial da empresa. Ela pode gerar aumento da produtividade e qualidade, redução de custos e crescimento da eficiência técnica, por meio do design de produtos, da otimização dos processos de produção, e da racionalização de componentes e materiais na produção de um produto.

O Portal Brasil (2010b) define startups como empresas recém-criadas, ou em desenvolvimento, de pequeno porte, que exerçam atividades diretamente ligadas à pesquisa e ao desenvolvimento, em geral. A Receita Federal (2004) define empresas de pequeno porte como a pessoa jurídica que tenha lucrado receita bruta superior a $R \$ 120.000$ e igual ou inferior a $R \$ 1.200 .000,00$, no ano-calendário.

É imprescindível que se tenha determinação, empatia pelos usuários e mente aberta quando se é fundador de uma startup. Adaptabilidade é outro 
fator importante, visto que começar uma startup é um processo de tentativa e erro, pois a inovação muitas vezes não é aceita logo de início (LIVENSTON, 2009).

Nesse contexto, propõe-se com esta pesquisa identificar estratégias passíveis de aplicação em um projeto de design de interiores para o escritório de uma startup, de forma que o ambiente empresarial transmita a identidade corporativa, a filosofia de trabalho e seja adequada aos usuários do espaço, de acordo com seu perfil. Definiu-se, assim, como objeto de estudo, uma startup belo-horizontina e, para ela, desenvolveu-se um projeto de design de interiores com o objetivo de promover a inovação.

Ao entender o conceito e a filosofia da empresa em questão, e das startups em geral, analisar o potencial de implementação do design nas empresas e identificar estratégias pertinentes ao projeto de design de interiores do escritório, é possível avaliar a importância do investimento em design por parte das organizações, aliado a outros fatores organizacionais, para que se diferenciem e tenham maiores chances de se manter no mercado. $O$ design de interiores, dessa maneira, por intermédio do planejamento da ocupação e do uso dos espaços - o que inclui os aspectos técnico-práticos, estéticos e simbólicos dos ambientes -, tem o potencial de transmitir a identidade da empresa, agregar valor à marca e promover maior produtividade e conforto para os usuários do espaço. Para Mozota (2011), o design é um processo de identidade que define a empresa, seus clientes e investidores, e é imprescindível para seu sucesso. Ele diferencia uma organização de seus concorrentes, construindo vantagens competitivas, e permite o aumento da participação da empresa no mercado em que atua, ou até a inserção em um novo mercado. Faz parte do papel do designer transcrever a filosofia da empresa, fazendo com que ela seja perceptível na escolha do mobiliário, na estrutura organizacional e na divisão dos espaços.

O autor acrescenta que empresas que investem em design obtêm melhores resultados em suas taxas de lucro e crescimento de vendas. $O$ design também pode contribuir para a promoção da inovação e pode potencializar a produtividade por parte dos funcionários de uma empresa, fator diretamente relacionado ao seu bem-estar. Especialmente em se tratando de startups, a promoção da inovação é crucial para que as empresasse mantenham no mercado, tendo em vista que a inovação é uma grande demanda de seu mercado e seus clientes (SEBRAE, 2011).

\section{FILOSOFIA DAS STARTUPS}

Ao definir-se uma startup, diversos fatores devem ser levados em consideração. Além das definições dadas por especialistas do mercado, existem outros aspectos subjetivos imprescindíveis para a compreensão desse termo, dentre eles, sua filosofia de trabalho. 
Ries (2011) afirma que startups são empresas que desenvolvem um serviço ou produto em um ambiente de extrema incerteza, ou seja, um mercado que lida com inovação, sem precedentes, e que, por esse motivo, não se tratam de empresas nas quais é adequado aplicar ferramentas tradicionais de planejamento.

Livenston (2009) destaca que quando se é fundador de uma startup, é imprescindível que se tenha determinação, mente aberta, empatia pelos usuários e disposição para mudar de ideia, ou seja, ser adaptável, pois começar uma startup é um processo de tentativa e erro, e todas as startups lidam com rejeição em algum momento, pois a inovação muitas vezes não é aceita logo de início.

No atual mercado competitivo, como aponta o SEBRAE (2011), o valor agregado aos produtos e serviços, por meio da inovação e diferenciação, é um fator imprescindível para a sobrevivência de um empreendimento. Os modelos tradicionais de gestão prezam o controle e o planejamento, e possuem atitudes conservadoras. Os modelos modernos são flexíveis, e priorizam a criatividade, a originalidade e a inovação.

Nos tempos atuais, o investimento em inovação é uma necessidade de qualquer empresa que pretende se manter no mercado. Nesse cenário, o conceito de startup se torna cada vez mais difundido com o passar do tempo, principalmente pela demanda por inovação, tanto por parte do mercado empresarial quanto por parte do consumidor o qual o mercado atende.

Ries (2011) destaca que, com o passar das décadas, o desenfreado crescimento tecnológico e, por consequência, a globalização, os consumidores se tornam cada dia mais exigentes na escolha de um produto ou serviço. A partir dessa constatação, nota-se a importância da inovação para as empresas nos dias atuais, um dos principais motivos da difusão do conceito de startups pelo mundo.

Para Livenston (2008), os aspectos prezados, e muitas vezes obrigatórios, por grandes empresas não são relevantes em se tratando de startups. As startups prezam por produtividade e resultados, e os meios utilizados para se chegar aos fins não são relevantes, pois variam de pessoa para pessoa, dependendo de seu perfil e estilo de trabalho.

Linvenston (2008) acrescenta que, aos olhos de muitas pessoas, as startups nem sequer parecem uma empresa. Seu modelo hierárquico, por exemplo, normalmente consiste em um modelo organizacional horizontalizado, ou seja, apesar de existir uma hierarquia, ela não é explícita. 


\section{A IMPORTÂNCIA DO INVESTIMENTO EM DESIGN}

Segundo Mozota (2011), os designers são especialistas que possuem conhecimento multidisciplinar, além da capacidade de conceber formas, e as técnicas por eles aplicadas envolvem, principalmente, inovação, estética e criação. Aspectos como a atenção ao usuário, criatividade, cuidado com os detalhes e iniciativa fazem do design uma estratégia em se tratando de administração de empresas.

Phillips (2008) destaca que, como resultado de estudos realizados pelo Ministério da Indústria da França, foi percebido que o uso do design por empresas, além de proporcionar vantagem competitiva, participa ativamente na cultura da empresa, por meio da melhoria de sua imagem e incentivo às suas equipes. $O$ autor observa ainda que outra pesquisa, realizada por Borja de Mozota, comprovou que o design também maximiza a eficiência da empresa, além de promover a gestão participativa da inovação e aperfeiçoar o gerenciamento de ideias por parte dos funcionários.

De acordo com Sorrento (2005), os funcionários de empresas frequentemente citam fatores relacionados ao design para justificar a escolha de um emprego ou uma empresa em detrimento de outro. De fato, muitos trabalhadores consideram questões relacionadas ao design ainda mais importantes que fatores financeiros, horários de trabalho e que a gestão da empresa. A partir dessas constatações, os gerentes identificaram a relação entre a satisfação de seus funcionários e o aumento de sua produtividade, e reconhecem que os dois estão diretamente associados a um ambiente de trabalho esteticamente atraente e funcional.

No âmbito empresarial, de acordo com Mozota (2011), o design é crucial para que haja coerência entre a identidade da companhia e sua marca, pois ele aborda diversos elementos de desempenho, tais como a comunicação de marketing, o comportamento e a aparência dos funcionários, as mensagens passadas por meio dos produtos ou serviços da empresa, além dos espaços, digitais ou físicos, que representam a organização e suas atividades.

O autor acrescenta que a criação do ambiente de trabalho de uma empresa influi diretamente na qualidade da produção, na constituição de uma cultura, e na comunicação de sua estratégia corporativa e de seu sistema de gestão. O design de interiores tem a capacidade de transmitir a identidade e filosofia da empresa em seu espaço de trabalho, fazendo com que esteja visivelmente presente na estrutura organizacional, por meio dos símbolos, signos, da disposição dos mobiliários e do layout.

Para Hok (2016), quando um bom projeto de design é executado em um ambiente de trabalho, esse espaço se torna uma poderosa ferramenta 
para o aumento da qualidade da performance dos funcionários da empresa, pois também propicia o aumento do bem-estar e da saúde dos usuários do espaço. Uma abordagem estratégica aplicada ao design de um escritório pode encorajar o trabalho em grupo, reestruturar os processos de trabalho e provocar uma mudança cultural positiva em uma companhia (ASID, 2016).

\section{ESTRATÉGIAS DE DESIGN EM AMBIENTES DE TRABALHO}

De acordo com o Portal Brasil (2010a), 89\% dos funcionários da Microsoft reconhecem que sua produtividade está diretamente ligada ao design de interiores do escritório. O ambiente de trabalho em si, os espaços empresariais e a disposição dos móveis são umas das principais preocupações em se tratando de aumentar a produtividade.

Ainda segundo o mesmo portal, muitas empresas, dentre elas Google e Facebook, integram espaços de relaxamento, lazer e confraternização em suas áreas de trabalho justamente para motivar sua equipe, e, consequentemente, a produtividade e a inovação por parte dos profissionais. Fazer pausas durante o expediente seja para socializar, se distrair, ou se exercitar, é uma boa estratégia para manter-se o mais produtivo possível.

A produtividade é otimizada por meio do recrutamento de funcionários de qualidade aliado ao alto nível de satisfação desses funcionários. A partir de uma abordagem estratégica aplicada ao layout da empresa, cujos objetivos da companhia e do projeto estejam em sintonia, é possível a remodelação dos processos de trabalho, minimizando as hierarquias, estimulando o trabalho em equipe e promovendo uma mudança cultural positiva dentro da empresa. (ASID, 2016; SORRENTO, 2005).

Para Gensler (2012), a tendência é que os ambientes de trabalho ideais promovam interação entre a equipe, além da concentração individual, ao desenvolver layouts e selecionar mobiliários que ofereçam aos usuários do espaço liberdade de locomoção e também mudança da disposição de seus postos de trabalho, de acordo com suas presentes necessidades. Essa tendência a personalizar e flexibilizar os ambientes de trabalho auxilia consideravelmente na maximização da capacidade humana de inovação e invenção.

A capacidade de foco e concentração é diretamente associada ao aumento da produtividade, e a interação e colaboração entre a equipe é diretamente associada à concepção de ideias inovadoras. Organizações que investem em espaços que permitam que as duas atividades sejam realizadas possuem maiores chances de obter sucesso. 
Hok (2016) afirma que a satisfação pessoal e a interação entre funcionários estão diretamente relacionadas, e ambas afetam na produtividade de um indivíduo. Funcionários que se relacionam com seus colegas tendem a ser mais produtivos e lucrativos do que os que não se relacionam. De acordo com Carroll (2013), a habilidade de promover a rápida comunicação e a interação entre os funcionários de uma empresa é um diferencial rumo à promoção da inovação. Para Sorrento (2005), o desenvolvimento de estações de trabalho convergentes para um eixo central, que possibilitem maior densidade de funcionários e facilitem a interação entre eles, permite que o indivíduo tenha privacidade e, ao mesmo tempo, a possibilidade de se comunicar e obter contato visual com seus colegas de trabalho. Segundo Hok (2016), se os funcionários possuem contato visual uns com os outros, a possibilidade de se conectarem e colaborarem entre si aumenta consideravelmente.

Mozota (2011) afirma que a escolha da melhor configuração do ambiente é realizada de acordo com as atividades nele executadas. Uma atividade que requer interação direta entre a equipe, por exemplo, deverá constituir de espaços abertos, para que promova a mesma. A socialização, a comunicação casual e a fluidez de procedimentos são incentivadas quando se reúne uma equipe em um mesmo espaço.

Segundo Cain (2012 apud HOK, 2016), o escritório bem projetado permite que seu usuário escolha o quão quer ser estimulado, ao intercalar espaços privativos e silenciosos e também espaços de lazer e interação. De acordo com Carroll (2013), por meio de layouts interativos e ambientes que possibilitem a individualidade, o ambiente de trabalho bem sucedido valoriza o espírito de equipe, impulsionando assim a missão e os negócios da empresa. Sorrento (2005) e Hok (2016) propõem a criação de setores de trabalho para áreas específicas, onde se é permitido trabalhar em silêncio, porém juntamente aos colegas, áreas onde se é permitido um nível maior de privacidade, e áreas de lazer e descontração, onde seja permitida a interação entre os funcionários da empresa.

Os ambientes de trabalho atuais devem ser flexíveis e adaptáveis a mudanças e à liberdade de escolha, com o enfoque no bem-estar do usuário do espaço e com o objetivo de inspirá-los (ADDI; LYTLE, 2000; CARROLL, 2013; PEPITONE, 2013). Não há mais espaço nas empresas modernas para as tradicionais compartimentações e para os postos de trabalho divididos em cubículos. Carroll (2013) acrescenta que os postos de trabalho tendem a ser menores e mais multifuncionais para facilitar a remodelagem do espaço de acordo com a atual demanda da empresa, com o mínimo de investimento possível a cada alteração de projeto.

Atualmente, há cada vez menos políticas criadas na base da liderança hierárquica, tais como postos de trabalho pré-definidos ou horários fixos de trabalho, e cada vez mais a cultura da auto liderança. Sorrento (2005) atesta que 
a percepção de hierarquia no espaço de trabalho pode afetar significantemente a maneira na qual os funcionários trabalham. É importante que os designers elaborem espaços de trabalho nos quais a ideia de hierarquia corporativa seja minimizada, ou até mesmo inexistente. Ao desenvolver e redesenhar estratégias, é possível substituir as abordagens tradicionais, baseadas em status, pelas abordagens atuais, baseadas nas tarefas realizadas no ambiente. Sorrento (2005) propõe também o desenvolvimento de equipes e salas de reuniões menos formais para que o fluxo de trabalho seja otimizado, promovendo assim o brainstorming e facilitando a solução de problemas complexos.

Um dos princípios básicos para promover o bem-estar e, consequentemente, o aumento da produtividade dos usuários do espaço, é a preocupação com seu conforto. O fornecimento de produtos ajustáveis e sistemas que proporcionam ao indivíduo controle sobre seu espaço de trabalho são o segredo para o desenvolvimento de um ambiente ergonomicamente correto (ADDI; LYTLE, 2000; HOK, 2016; SORRENTO, 2005).

A ergonomia engloba não só o conforto por meio dos produtos que utilizamos, mas também o conforto termal e acústico. Hok (2016) afirma que o conforto termal é obtido por meio da combinação harmoniosa entre fluxo de ar, umidade e temperatura, e que a partir do momento que o controle desses fatores é proporcionado aos usuários do espaço, há o aumento da produtividade por parte dos mesmos. Sorrento (2005) acrescenta que a reclamação mais frequente por parte dos funcionários de uma empresa a respeito do ambiente de trabalho é a falta de controle sobre esses fatores. Uma estratégia de design que pode ser aplicada para proporcionar o aumento do conforto termal é a acessibilidade do controle desses fatores por parte dos funcionários, setorizados individualmente por áreas determinadas (salas de reunião, cada determinado setor de trabalho, etc.). Outra estratégia seria a disposição acessível de janelas, com o objetivo de maximizar a entrada de luz natural, fluxo do ar e controle de temperatura.

O conforto acústico também é de suma importância para o bem-estar de um funcionário produtivo. Segundo Hok (2016), barulhos podem aumentar ou prejudicar a produtividade de um indivíduo, dependendo da atividade por ele realizada e de sua preferência pessoal. Algumas medidas podem ser tomadas para evitar que ruídos indesejados afetem o desempenho de determinados funcionários. É importante separar atividades e ambientes barulhentos de ambientes que requerem silêncio e concentração, e deve-se também criar espaços de lazer para que os funcionários possam interagir tranquilamente, sem a possibilidade de provocar incômodo em seus colegas que estiverem trabalhando.

Além de fatores funcionais, fatores estéticos também influenciam o nível de produtividade dos usuários de um espaço. A falta de estímulo do funcionário durante o período de trabalho pode afetar a sua habilidade de 
manter-se focado. A utilização de elementos de cores neutras em demasia, mesmo volume e textura podem influenciar negativamente na produtividade do usuário do espaço. Hok (2016) sugere a introdução de cores, elementos gráficos, estampas e texturas variadas para que haja o estímulo dos sentidos dos funcionários da empresa. Bavaresco (1994) ressalta que o uso combinado de cores quentes e frias proporciona resultados positivos, tanto no aspecto psicológico quanto no físico, reduzindo ou ampliando ambientes. De acordo com a Scientific American Brasil (2015), a cor azul é corretamente empregada em ambientes onde seja interessante possuir uma visão holística e generalizada. Hok (2016) acrescenta que, por esse motivo, é bem empregada quando se deseja incentivar a criatividade nos empregados. Bavaresco (1994) afirma que a cor amarela está diretamente ligada ao estímulo à atividade intelectual, e Hok (2016) adiciona que ela é bem aplicada em ambientes relacionados a tomadas de decisões. A cor vermelha, por sua vez, estimula a sensação de força e energia, e é associada à ambição e vitalidade. Segundo Hok (2016), o uso das cores deve ser equilibrado e variado nos espaços de trabalho.

Outro fator que contribui para o aumento da produtividade de um indivíduo é sensação de proximidade com o meio natural. Para Hok (2016), é saudável que o ser humano possua uma conexão com a natureza e o contato, mesmo que por tempo limitado, com o ambiente externo é benéfico para o bem-estar de um indivíduo e, consequentemente, para o aumento de sua produtividade. As pessoas tendem a preferir ambientes cercados por elementos naturais e é importante que isso seja replicado também nos ambientes internos que frequentam. Algumas estratégias de design que podem ser aplicadas ao projeto são a preferência por vistas naturais e agradáveis sempre que possível, o uso do vidro (quando não houver a demanda por privacidade) como divisórias de ambiente, para propiciar maior visibilidade a essas vistas e o incentivo à utilização de espaços externos pelos funcionários. Sorrento (2005) sugere também o uso de cores claras para o teto, para promover a reflexão da luz natural no ambiente de trabalho, aliado ao uso de iluminação indireta, o que contribui para a redução do ofuscamento da visão dos usuários do espaço.

\section{EXEMPLO DE APLICAC̣̃̃O EM UMA STARTUP}

A empresa analisada é uma startup situada na região centro-sul de Belo Horizonte. Ela foi fundada por três co-fundadores e oferece serviço de auxílio a empresas por meio do marketing de conteúdo. Em entrevista, um dos fundadores da startup define marketing de conteúdo como uma estratégia estruturada para elaborar e disseminar conteúdo, com o objetivo de atrair e gerar uma relação de confiança com o cliente, além de amplificar a presença de marca da empresa. O marketing de conteúdo se baseia na premissa que, ao oferecer algo de valor para seu cliente, a empresa cria um relacionamento baseado na confiança e não nos modelos tradicionais de marketing, algumas vezes invasivos e explícitos. 
A startup foi fundada em 2013 e é referência em sua área de atuação, obtendo destaque em diversas revistas, jornais e web sites, nacionais e internacionais, do ramo da tecnologia e empreendimento.

De acordo com o entrevistado, sua startup tem como visão tornarse a principal referência de marketing de conteúdo no Brasil, e quer passar a imagem de uma startup moderna, desvinculada de empresas tradicionalistas, em concordância com sua identidade. A empresa possui um ambiente de trabalho informal e descontraído, pois foca em resultados, e não em processos. O co-fundador define a cultura da startup como "liberdade e responsabilidade", pois cada membro da equipe realiza sua atividade da forma que julga melhor, desde que produza os resultados desejados. Na empresa há a valorização das ideias e conhecimentos de cada membro da equipe, desde que o mesmo seja proativo, se comprometa e se dedique a ela.

O objetivo do projeto de design de interiores desenvolvido para a startup estudada foi inserir sua filosofia de trabalho em seu espaço físico, com o intuito de valorizar sua identidade corporativa, além de estimulara promoção da inovação e da produtividade por parte dos funcionários no ambiente de trabalho. $\mathrm{O}$ enfoque do projeto foram os funcionários, investidores e clientes em potencial da empresa.

Dentre as estratégias de design citadas nesse artigo, algumas foram aplicadas ao projeto de design de interiores da empresa estudada, levando em consideração suas limitações. O escritório da startup analisada localiza-se em uma casa antiga cuja estrutura é toda em alvenaria. Essa estrutura gerou a impossibilidade de alterações significativas nas paredes existentes, dificultando a implantação de estratégias que seriam importantes para o sucesso do projeto. Portanto, alternativas foram adaptadas para que fosse possível o desenvolvimento do projeto de acordo com sua demanda. Dentre os fatores que não puderam ser explorados em toda sua potencialidade, encontram-se questões referentes a otimização da iluminação e do fluxo de ar natural.

Os fundadores da empresa não pretendiam permanecer por um grande período na atual localização do escritório, portanto era necessário que o mobiliário desenvolvido fosse facilmente adaptado para outra possível sede. O escritório é composto por seis ambientes, além da copa e da instalação sanitária, e todas as áreas comuns podem ser utilizadas como área de trabalho. A descrição de todos os ambientes analisados se encontra no quadro 1. 
Quadro 1 - Ambientes do escritório analisado.

\begin{tabular}{|c|c|}
\hline Ambiente & Função \\
\hline Fun Place & $\begin{array}{l}\text { Ambiente de lazer e jogos, onde se é possível interagir e } \\
\text { descontrair. }\end{array}$ \\
\hline Sala de operações & $\begin{array}{l}\text { Ambiente de trabalho onde é necessário silêncio, pois a } \\
\text { atividade requer foco por parte dos funcionários. }\end{array}$ \\
\hline Sala & $\begin{array}{l}\text { Ambiente de trabalho onde são feitas ligações e calls, por } \\
\text { meio do notebook. Deve ser separada da área de operações, } \\
\text { uma vez que a atividade provoca ruídos. }\end{array}$ \\
\hline $\begin{array}{l}\text { Sala de reunião de } \\
\text { vendas }\end{array}$ & $\begin{array}{l}\text { Área de pequenas reuniões com funcionários, clientes e } \\
\text { investidores. Quando não utilizada para essa finalidade, } \\
\text { também pode ser utilizada como espaço de trabalho para o } \\
\text { funcionário que assim desejar. }\end{array}$ \\
\hline $\begin{array}{l}\text { Sala de relaxamento / } \\
\text { trabalho }\end{array}$ & $\begin{array}{l}\text { Pode ser utilizada para descanso ou para trabalho, a critério } \\
\text { do funcionário. }\end{array}$ \\
\hline $\begin{array}{l}\text { Área de reuniões } \\
\text { informais / bar }\end{array}$ & $\begin{array}{l}\text { Área de interação, semiaberta, nos fundos da empresa, } \\
\text { destinada aos frequentes eventos e reuniões informais } \\
\text { dos membros da equipe. Também pode ser utilizada como } \\
\text { espaço de trabalho para o funcionário que assim desejar. }\end{array}$ \\
\hline
\end{tabular}

Fonte: Os autores.

Os ambientes da empresa foram projetados com o intuito de promover a interação entre os funcionários, seja nos espaços de trabalho ou lazer. As figuras 1 e 2 são referentes ao projeto da sala de operações.

Figura 1 - Sala de Operações.

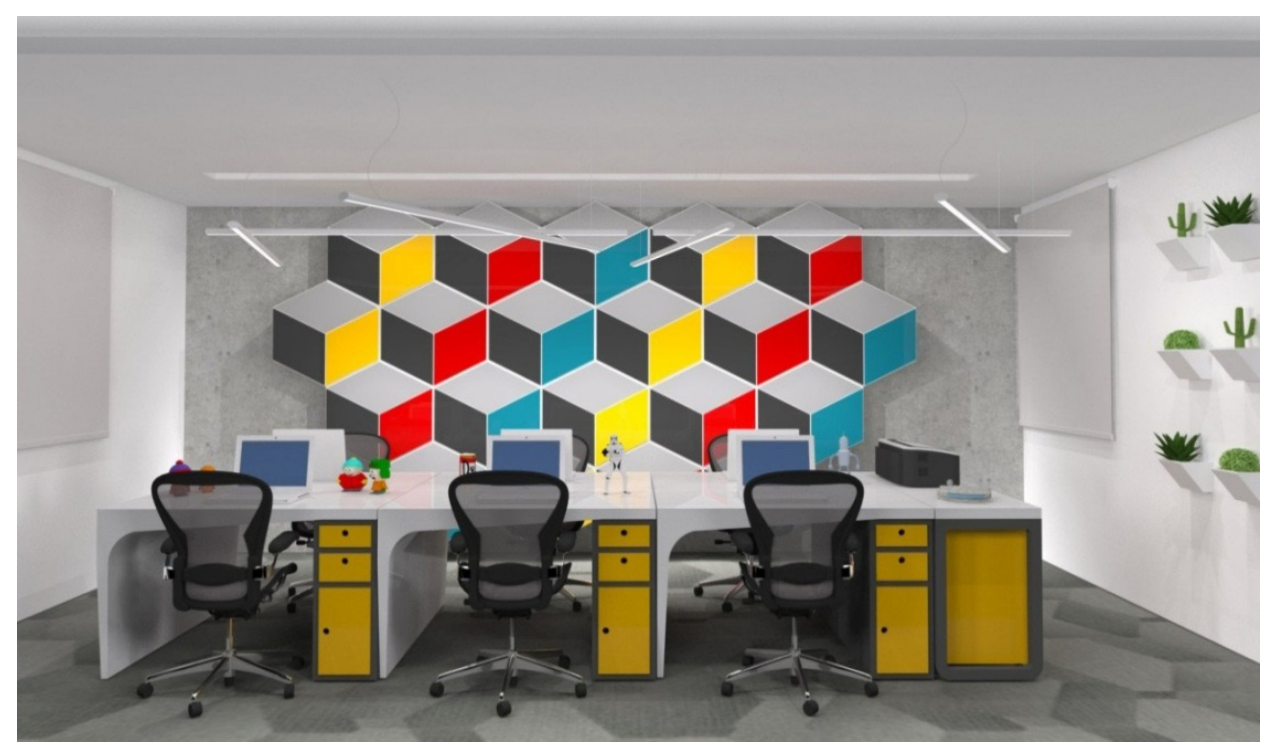

Fonte: Os autores.

Todas as estações de trabalho convergem para um eixo central (ver figuras 1, 2 e 3), possibilitando maior interação entre os funcionários, e o mesmo 
pode ser observado na área semi aberta (figura 6). Todos os postos de trabalho são iguais, e as salas de trabalho são divididas por uso, e não por hierarquia.

Figura 2 - Sala de Operações - Vista Lateral.

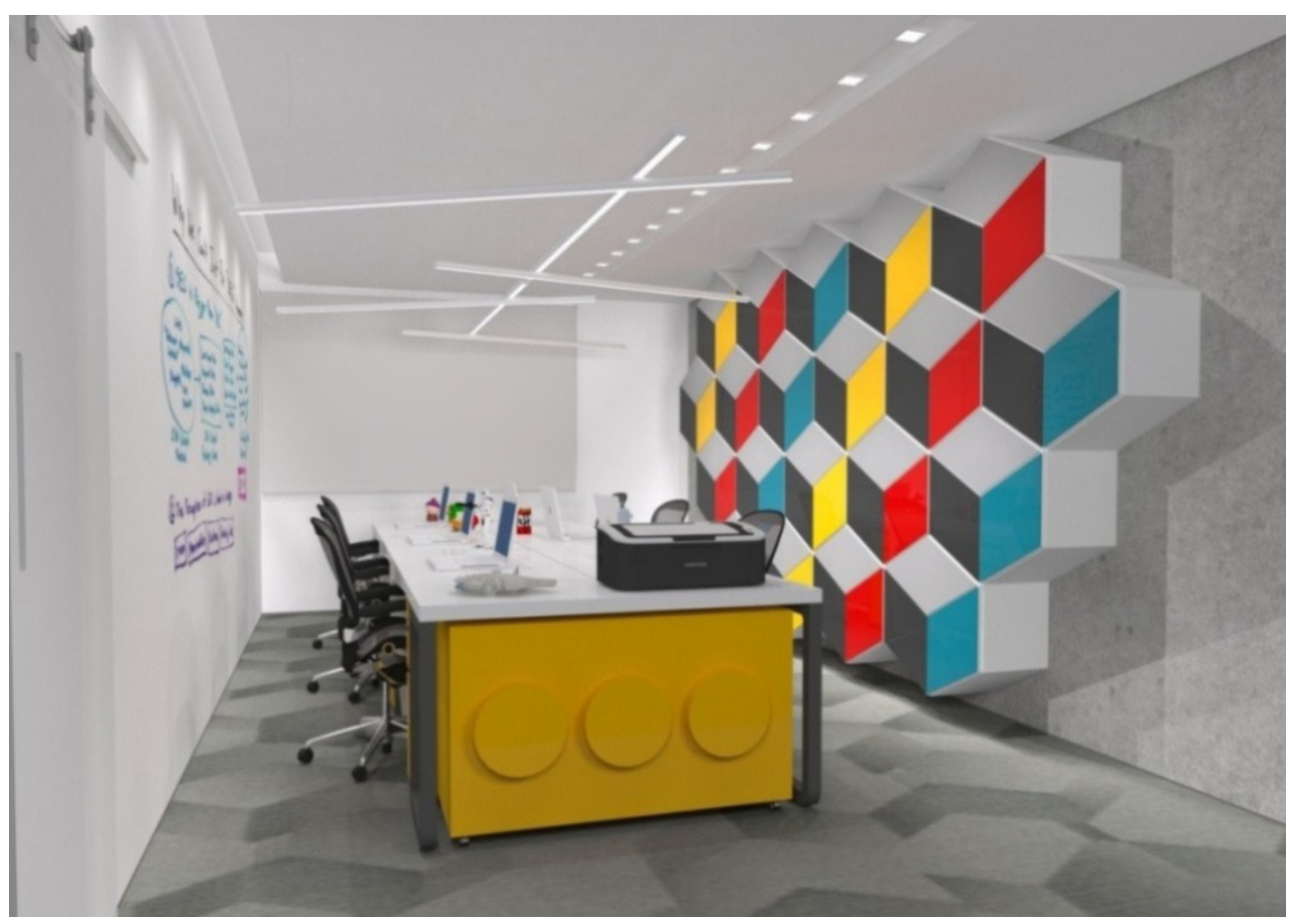

Fonte: Os autores.

A figura 3 apresenta o ambiente de trabalho onde são feitas ligações e calls. Dado a produção de ruídos, a Sala de Vendas é separada na sala de operações.

Figura 3 - Sala de Vendas.

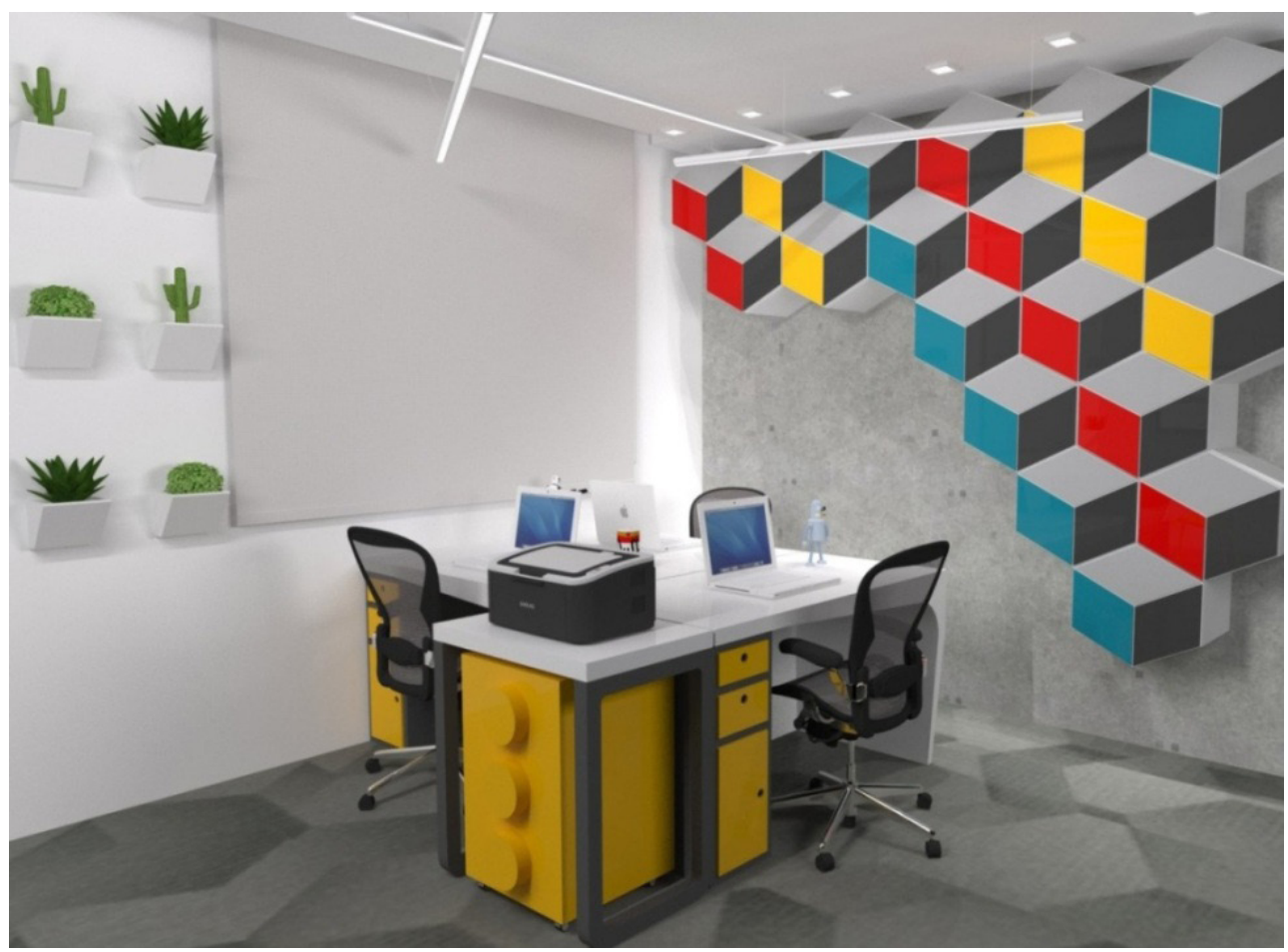

Fonte: Os autores. 
A figura 4 apresenta a área de pequenas reuniões com funcionários, clientes e investidores. Também segregada da área de operações, para evitar possíveis ruídos, pode ser utilizada como espaço de trabalho para o funcionário que assim desejar.

O mobiliário da empresa foi pensado para que grande parte pudesse ser reajustada à futura sede da empresa, e os postos de trabalho foram projetados de forma a atender às necessidades ergonômicas dos funcionários. As mesas possuem dimensões que atendem às normas de ergonomia referentes ao espaço trabalhado, que abrangem as necessidades de um ser humano de porte médio, e as cadeiras são ajustáveis, para que cada indivíduo possa adequá-las à suas especificidades físicas. Os móveis e os postos das áreas de trabalho são de pequeno porte (conforme Figura 8), e, devido à falta de espaço, as paredes foram utilizadas para fixação de móveis de armazenagem de papéis e documentos. Cada hexágono é instalado individualmente, sendo assim facilmente transportados e reorganizados em qualquer espaço.

Figura 4 - Sala de Reunião e de Vendas.

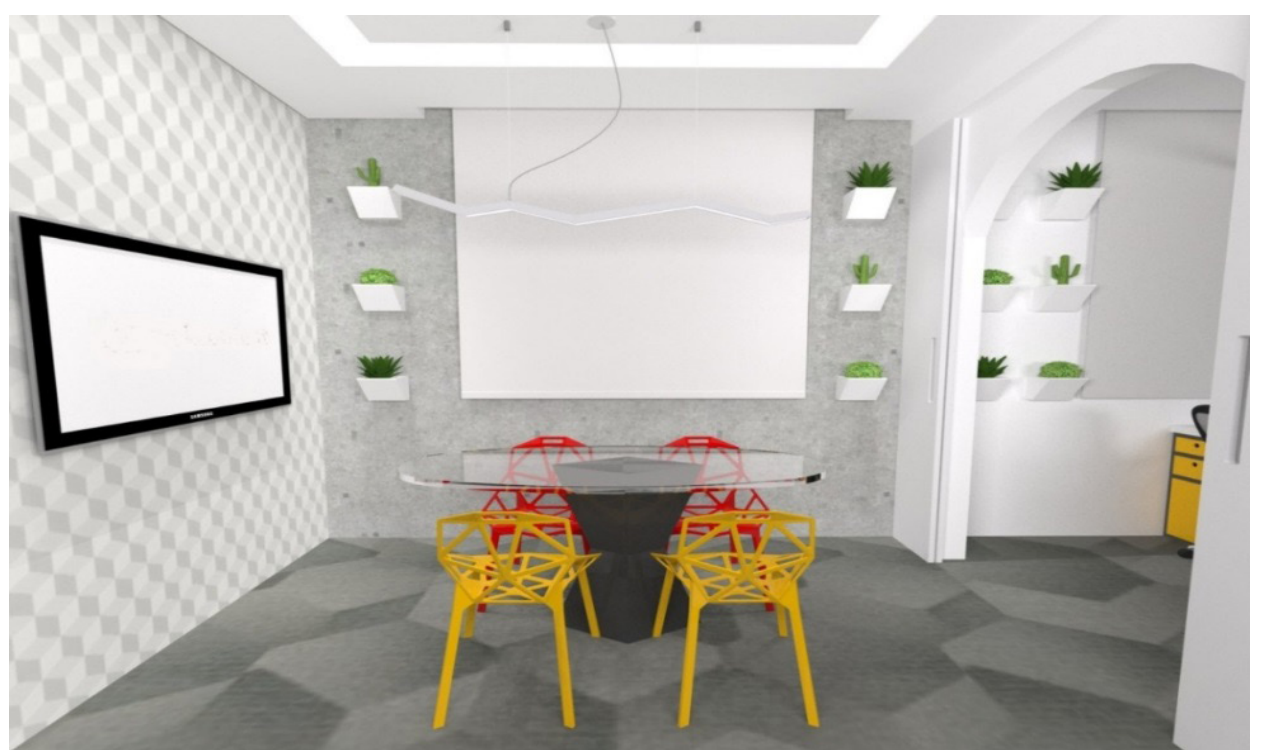

Fonte: Os autores.

Alguns fatores ergonômicos não puderam ser amplamente considerados devido às limitações da construção. Pelo fato de o espaço disponível ser uma casa antiga e estruturada somente em alvenaria, não foi possível realizar alterações arquitetônicas que pudessem auxiliar na aplicabilidade de estratégias significativas para promover acesso à luz natural e ao conforto termal por parte dos usuários do espaço. Foram previstos equipamentos de controle de temperatura individuais em cada ambiente, para promover maior conforto térmico, e foi utilizada iluminação direta e indireta na maioria dos espaços, para que os usuários tivessem opção de escolha referente à iluminação. Os fatores relacionados ao contato com o meio natural também foram comprometidos. A alternativa identificada foi a especificação de plantas de pequeno porte para 
áreas internas, limitadas aos espaços restritos e apoiadas em cachê pôs fixados na parede, para que os funcionários tivessem contato, mesmo que limitado, com a natureza.

Figura 5 - FunPlace (Sala de Diversões).

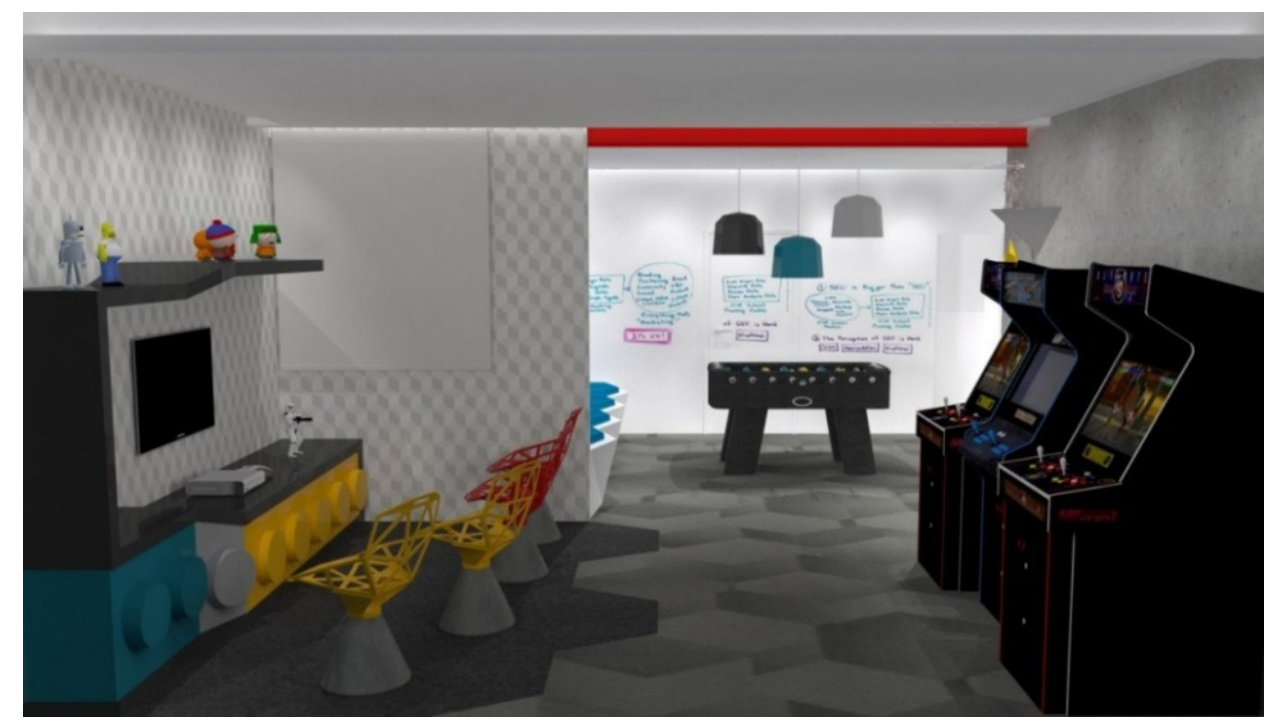

Fonte: Os autores.

Além da promoção da inovação e do aumento da produtividade, o objetivo do projeto em questão foi a valorização da identidade corporativa da startup. A partir das informações obtidas por meio da entrevista com um dos co-fundadores da empresa, percebe-se que a imagem da startup deve ser associada à modernidade e ao dinamismo. A empresa deve ser vista como em constante evolução e atualização, ao invés de uma empresa estagnada e tradicional. Segundo Sarro (2009), a partir do estudo das Leis da Gestalt (conhecidas no Brasil por Teoria da Forma), a percepção humana em relação às linhas diagonais mostra uma associação ao dinamismo e ao movimento, ao contrário das linhas verticais, por exemplo, que são associadas à precisão e estabilidade. Uma das formas amplamente utilizadas no projeto de design de interiores foi o hexágono, por ser uma forma composta também por linhas diagonais e por remeter à inspiração do conceito do projeto: a organização eficiente de uma colmeia, definida com base na cultura de "liberdade e responsabilidade" da empresa projetada.

As mesas e cadeiras da área semi aberta são dobráveis, permitindo assim que o ambiente seja utilizado como área de reuniões ou como espaço livre para os eventos da empresa. Buscou-se o equilíbrio das cores nos ambientes por meio do uso de cores frias e quentes. A predominância foi de cores neutras com o uso pontual das cores primárias, pelo fato de os espaços serem compactos (como podem ser observados nas figuras 6 e 7). 
Figura 6 - Área de Reuniões Informais/Bar.

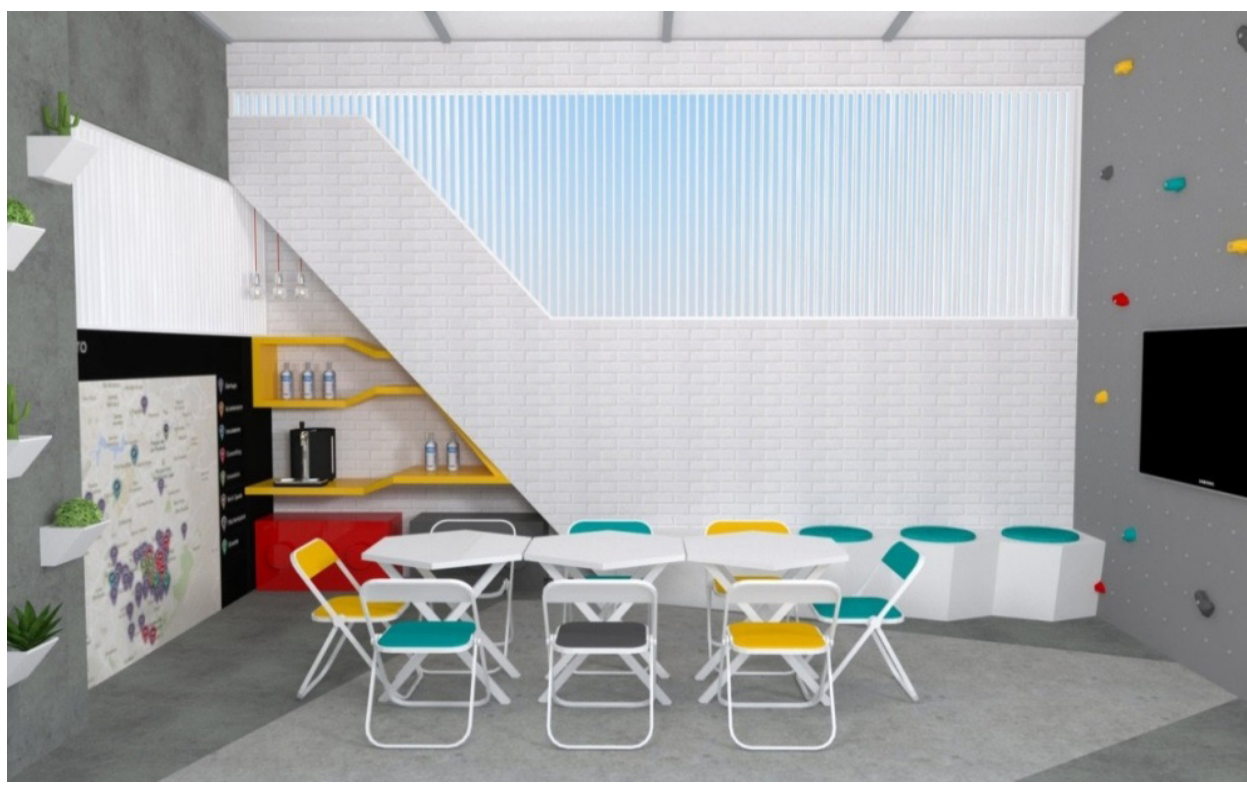

Fonte: Os autores.

Figura 7 - Sala de Relaxamento/Trabalho.

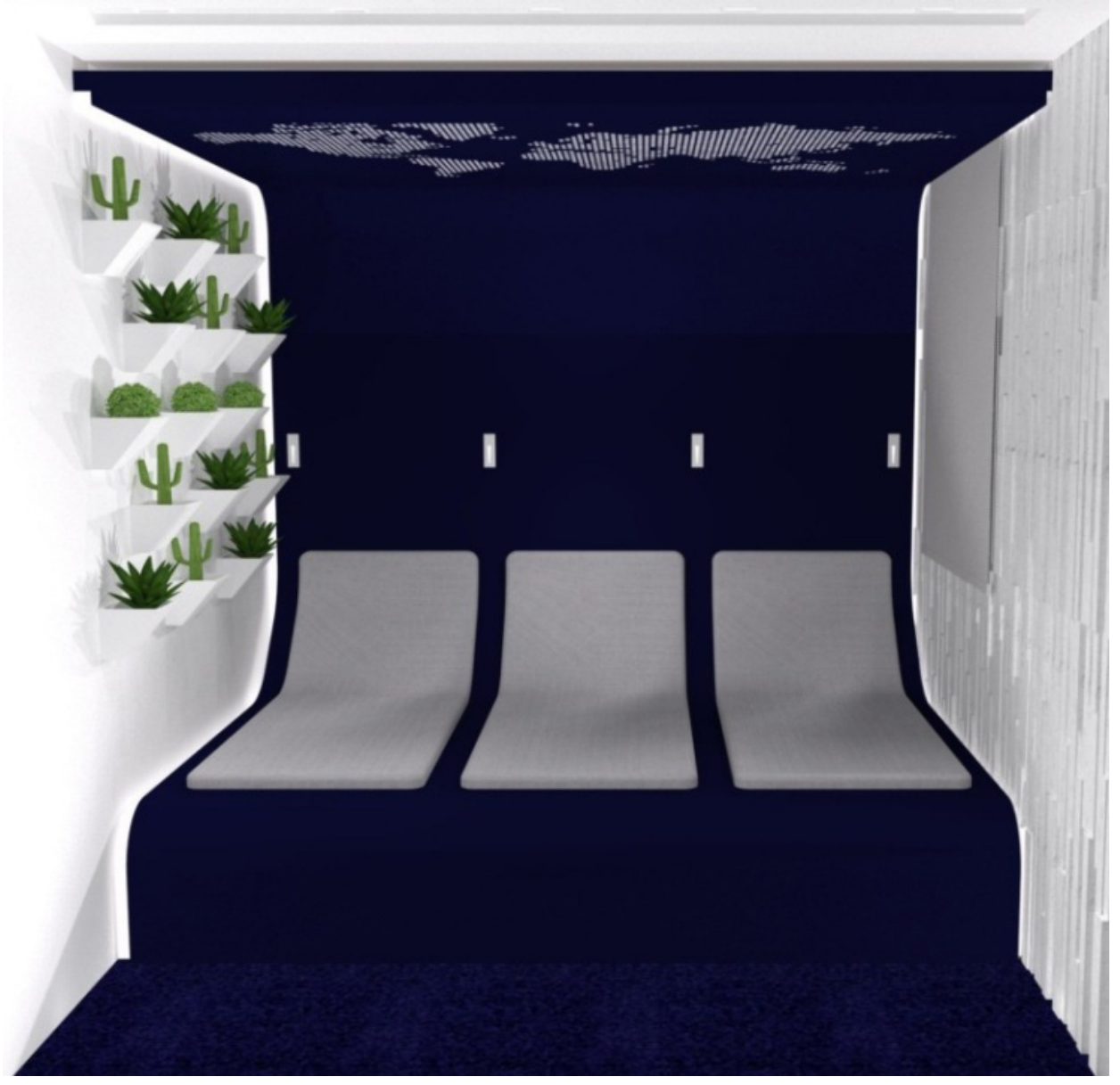

Fonte: Os autores. 
Figura 8 - Planta Layout do Imóvel.

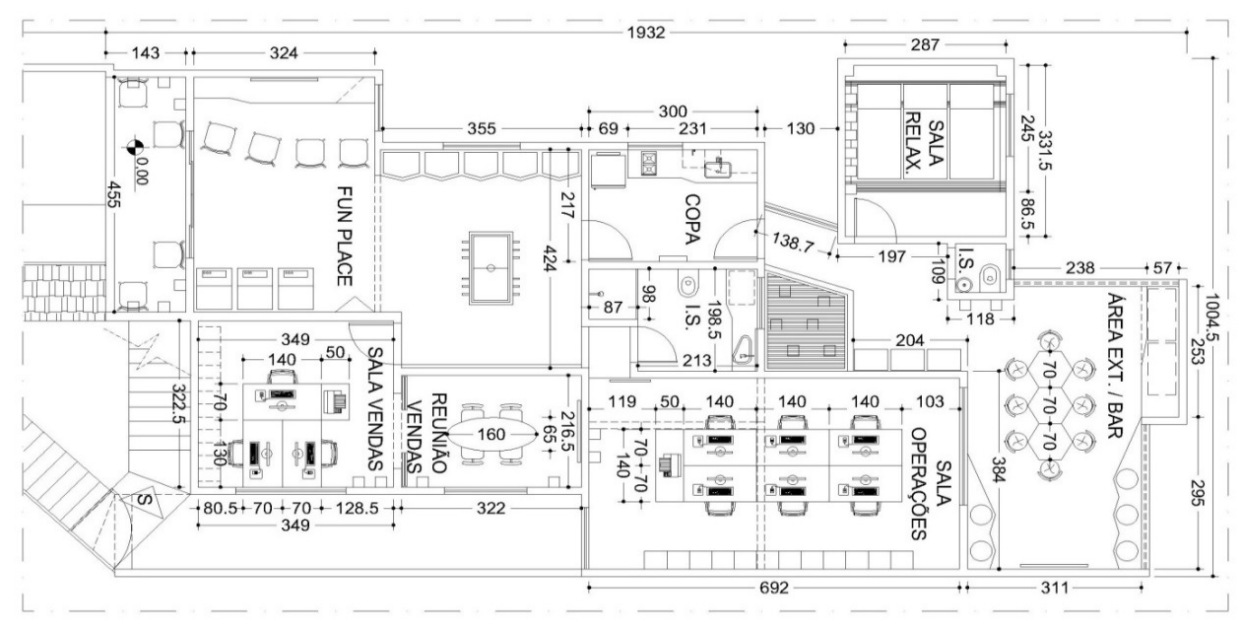

Fonte: Os autores.

Observa-se, a partir da figura 8, a disposição do mobiliário nos ambientes projetados, além de suas respectivas dimensões. Conforme mencionado previamente, o mobiliário situado em áreas de trabalho busca atender às necessidades ergonômicas dos usuários, além de ser funcional e adequado à atividade exercida, mas também é importante que o mesmo não obstrua a área de circulação, tendo em vista que o imóvel é segmentado em espaços compactos. Dessa forma, é importante que as mesas e locais de armazenagem de equipamentos sejam de pequeno porte e, assim, também haja maior flexibilidade em sua disposição.

\section{CONSIDERAC̣ÕES FINAIS}

A presente pesquisa teve como objetivo identificar estratégias a serem aplicadas no projeto de design de interiores em escritórios de startups. Assim, buscou-se identificar formas pelas quais o designer de interiores pudesse auxiliar na transmissão da identidade corporativa da empresa e de sua filosofia de trabalho, além de promover a inovação e a produtividade por parte dos funcionários da empresa. $O$ trabalho também procurou exemplificar a estruturação de um projeto de design de interiores, levando-se em consideração a adequação dos usuários ao espaço, de acordo com seu perfil analisado e dos limites estruturais da área estudada.

Observa-se que, no âmbito empresarial, o design apresenta papel de destaque para que haja coerência entre a identidade da companhia e sua marca (MOZOTA, 2011). Dada a característica inovadora das startups, observou-se uma predominância de linhas diagonais na composição dos ambientes. Isso porque, de acordo com Sarro (2009), linhas diagonais são associadas são dinamismo e ao movimento, ao contrário das linhas verticais, por exemplo, associadas à precisão e estabilidade.

Destaca-se a importância da preocupação com o conforto termal e acústico, fatores essenciais para a garantia dobem estar de um funcionário 
produtivo. Dessa forma, percebe-se a necessidade de se levar em consideração o nível de ruídos dos ambientes analisados. Um escritório bem projetado permite que seu usuário escolha seus estímulos, interpondo espaços privativos e silenciosos e também espaços de lazer e interação (CAIN, 2012 apud HOK, 2016).

Fatores estéticos também devem ser levados em consideração, uma vez que a falta de estímulo do funcionário durante o período de trabalho pode alterar sua habilidade em manter-se focado. Por fim, a sensação de proximidade da natureza foi identificada na literatura como um fator capaz de elevar a produtividades dos indivíduos no âmbito empresarial (HOK, 2016).

Como principal limitação do trabalho, destaca-se o fato de não ter havido um processo de feedback após a implementação do projeto. Assim, o presente estudo não foi capaz de identificar a reação dos usuários do espaço à estrutura proposta, além de não ser capaz de obter resultados quantitativos e qualitativos em relação a um possível aumento de produtividade ou mesmo melhora da sensação de bem-estar experimentada pela equipe.

Assim, destaca-se como possibilidade de futuras pesquisas, a aplicação e avaliação futura de projetos voltados para startups. Ainda nesse sentido, dada a capacidade do designer de interiores de auxiliar o ambiente empresarial nas suas mais variadas esferas, sugere-se também que pesquisas detectem a especificidade de cada ramo de negócios, além das necessidades de adaptação dos projetos de design de interiores, de acordo com características peculiares às empresas. Não obstante, mostra-se relevante a compreensão da percepção do público, em geral, a respeito dos resultados gerados pelos trabalhos executados pelos profissionais da área.

\section{REFERÊNCIAS}

ADDI, Gretchen; LYTLE, Jacqueline. Interior design. In: DEMKIN, Joseph A. (ed.). The Architect's handbook of professional practice. New York: The American Institute of Architects, 2000. p. 1-7.

ASID. Impact of Design on Productivity. Disponível em: https://wwwasidorg/ content/impact-design-productivity\#VuYjBPkrLct. Acesso em: 22 jan. 2016.

BAVARESCO, N. A influência das cores na criatividade. 1994. Disponível em: http://www.sato.adm.br/artigos/a_influencia_das_cores_na_criati.htm. Acesso em: 22 jan. 2016.

CARROLL, A. The smarter workplace international sand sources. Disponível em: http://wwwinteriorsandsourcescom/article-details/articleid/15645/title/ the-smarter-workplaceaspx. Acesso em: 20 dez. 2015.

GENSLER. What we've learned about focus in the workplace. 2012.

Disponível em: http://www.gensler.com/uploads/documents/Focus_in_the_ Workplace_10_01_2012.pdf. Acesso em: 3 mar. 2013. 
HOK. Workplace strategies that enhance performance, health and wellness. Disponível em: http://wwwhokcom/thought-leadership/workplace-strategiesthat-enhance-human-performance-health-and-wellness/. Acesso em: 10 jan. 2016.

LASTRES, Helena; ALBAGLI, Sarita. Informação e globalização na era do conhecimento. Rio de Janeiro: Editora Campus, 1999.

LIVENSTON, Jessica. Fouders at work: stories of startup's early days. Nova lorque: Apress, 2008.

LIVENSTON, Jessica. Startup: fundadores da Apple, do Yahoo!, Hotmail, Firefox, e Lycos contam como nasceram suas empresas milionárias. Rio de Janeiro: Agir Editora, 2009.

MOZOTA, Brigitte. Gestão do design: usando o design para construir valor de marca e inovação corporativa. São Paulo: Bookman, 2011.

PEPITONE, Sara. Workplace strategy's impaction design. Disponível em: http://wwwinteriordesignnet/projects/9571-workplace-strategys-impact-ondesign/, 2013. Acesso em: 17 dez. 2015.

PHILLIPS, Peter. Briefing: a gestão do projeto de design. São Paulo: Blucher, 2008.

PORTAL BRASIL. Aumente a produtividade. 2010a. Disponível em: http:// www.brasil.gov.br/empreendedor/profissionalizacao. Acesso em: 12 jun. 2013.

PORTAL BRASIL. Startup. 2010b. Disponível em: http://www.brasil.gov.br/ empreendedor/primeiros-passos/startup. Acesso em: 3 mar. 2013.

RECEITA FEDERAL. Microempresa (ME) e empresa de pequeno porte (EPP). 2004. Disponível em: http://www.receita.fazenda.gov.br/pessoajuridica/ dipj/2004/pergresp2004/pr110a202.htm. Acesso em: 3 mar. 2015.

RIES, Eric. The lean startup: how today's entrepreneurs use continuous innovation to create radically successful business. Nova lorque: Crown Business, 2011.

SARRO, Ed Marcos. Estruturas icônicas nas cartilhas de treinamentos quadrinizadas. 2009. Dissertação (Mestrado em Design e Arquitetura) Universidade de São Paulo, São Paulo, 2009.

SCIENTIFIC AMERICAN BRASIL. Cores estimulam atividade cerebral: pesquisadores verificaram que o vermelho ajuda na concentração e o azul libera a mente. Disponível em: http://www2.uol.com.br/sciam/noticias/cores_ estimulam_atividade_cerebral.html. Acesso em: 27 jun. 2015.

SEBRAE. Termo de referência para atuação em design. São Paulo: SEBRAE, 2011.

SORRENTO, Linda. Designing better workplaces. Washington: ASID American Society of Interior Designers, 2005. 